\title{
Single-session laparoscopic cystectomy and nephroureterectomy
}

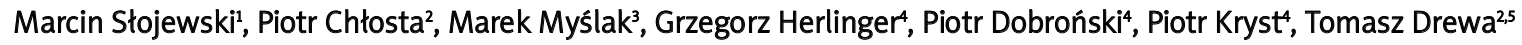 \\ 1Department of Urology and Urological Oncology, Pomeranian Medical University, Szczecin, Poland \\ 2Department of Urology, Holy Cross Cancer Centre, Kielce, Poland \\ ${ }^{3}$ Department of Nephrology and Transplantology, Pomeranian Medical University, Szczecin, Poland \\ ${ }^{4}$ Department of Urology, Bielanski Hospital, Warsaw, Poland \\ ${ }^{5}$ Department of Tissue Engineering, Nicolaus Copernicus University, Bydgoszcz, Poland
}

Videosurgery Miniinv 2013; 8 (2): 158-161

DOI: 10.5114/wiitm.2011.31946

\begin{abstract}
Patients with high grade and/or muscle invasive bladder cancer and with concomitant diseases of the upper urinary tract, e.g. urothelial tumors (transitional cell carcinoma - TCC) or afunctional hydronephrotic kidneys, may be candidates for simultaneous cystectomy and nephroureterectomy. Although the progress in laparoscopic techniques made these procedures feasible and safe, they are still technically demanding so only experienced surgeons can perform them. The aim of the study is to report our experience with laparoscopic simultaneous en bloc resection of the urinary bladder together with unilateral or bilateral nephroureterectomy in patients with TCC. Our material consists of three cases operated on in three centers between 2002 and 2011. After having completed bilateral (1 case) or unilateral (2 cases) nephroureterectomy, we performed radical cystectomy with pelvic lymph node dissection. All the specimens, including the kidneys, ureters, bladder, and reproductive organs in the female, were collected in endobags and were retrieved en bloc using hypogastric incision in the male patient and the vaginal route in the female patients. The demographic and perioperative information was collected and analyzed. All procedures were completed laparoscopically without the need of conversion to open surgery. No major intra- or postoperative complications were observed. Only 1 patient suffered from prolonged lymphatic leakage. From our experience we can conclude that single-session laparoscopic cystectomy and nephroureterectomy are technically feasible and safe, and may be offered for the treatment of selected cases of TCC of the urinary tract.
\end{abstract}

Key words: laparoscopy, nephroureterectomy, cystectomy, pelvic exenteration.

\section{Introduction}

Transitional cell carcinoma (TCC) can involve the urinary bladder as well as ureters and the renal pelvicalyceal system. Tumors of the upper urinary tract are found in $2-4 \%$ of patients with affected bladder; however, bilateral lesions are rare, and they have been reported at varying rates in the literature [1, 2]. Therefore most authors recommend lifelong upper urinary tract surveillance in patients with bladder cancer.
Radical cystectomy is the treatment of choice for multiple and/or muscle invasive bladder cancer, and radical nephroureterectomy with bladder cuff excision is considered the standard treatment for highgrade, recurrent, invasive or large transitional cell carcinoma of the upper urinary tract. The advances in minimally invasive techniques have allowed both procedures to be performed by laparoscopic techniques [3-7]. The era of modern urolaparoscopy 
began in 1991 when Clayman et al. performed the first laparoscopic nephrectomy and nephroureterectomy (laparoscopic radical nephrectomy, LRN) [8, 9]. Parra et al. described the first case of laparoscopic cystectomy in 1992 on a 27-year-old paraplegic woman with a pre-existing cutaneous diversion whose neurogenic bladder was removed due to pyocystis [10]. The first case of laparoscopic radical cystectomy (LRC) for bladder cancer was described by Sanchez de Badajoz et al. [11]. Since that time several series of pure laparoscopic or robotic-assisted cystectomies have been published, demonstrating their feasibility, safety and similar functional and oncological outcomes when compared to those after open surgery [12-14].

\section{Case report}

Our material consists of three cases of laparoscopic cystectomy and bilateral or unilateral nephroureterectomy performed simultaneously between 2002 and 2011. The patients were operated on by two surgeons (M.S. - cases 1 and 3; P.Ch. - case 2) in three centers. Demographic data and perioperative parameters are collected in Table I. The indications for surgery were TCC of the bladder with afunctional kidney due to obstruction (2 cases) and bladder cancer with coexisting bilateral TCC tumors of the upper urinary tract (1 case). The surgical technique with transperitoneal access was similar in all cases. All procedures were completed laparoscopically without conversion to open surgery. All patients required intra- or postoperative blood transfusion. The placement and number of working ports used differed depending on the local conditions and the surgeon's preferences. In all cases the camera port throughout the entire procedures was placed in the umbilical or periumbilical site. Nephroureterectomy was performed as the initial proce- dure (patients 1 and 3) with the patient placed in the flank position, or after cystectomy (patient 2). The distal part of the ureters was dissected cephalad down to the pelvic part and was not cut off from the bladder in order to remove the specimen en bloc. In case 3 the left nephroureterectomy was performed first, then after repositioning of the patient, the kidney on the other side was removed by the same surgical technique and with mirrored ports placement. Renal vessels were secured with an endoGIA stapler and hem-olocks (cases 1 and 3) or with titanium clips (case 2), depending on their diameter. After nephroureterectomy, the patients were moved into the lithotomy-Trendelenburg position. Two or three additional ports were used in a hypogastrium to provide proper access to the pelvic area. Then the cystectomies including prostatectomy (case 2) and hysterectomy and bilateral salpingo-oophorectomy (cases 1 and 3) were performed. The hemostasis of lateral vesical pedicles and superficial and deep venous complexes were obtained with monopolar and bipolar scissors, stapling devices and metal clips. In case 3 cystectomy was almost fully completed with a harmonic knife. In order to avoid cancer seeding the vesical neck was secured in all cases with the balloon of Foley catheter left in the lumen of the bladder. Following oncological principles the lymphatic tissue surrounding iliac vessels and from the obturator fossa was removed in all cases. In every case the specimen was placed in a plastic endoscopic bag and removed en bloc through the incision in the lower right abdomen (case 2) or transvaginally (cases 1 and 3) (Photo 1). In cases 1 and 2, where unilateral nephroureterectomies were performed, ureterocutaneostomies were applied as the method of urine derivation. In both cases ureters were implanted in the location of laparoscopic ports. Operative

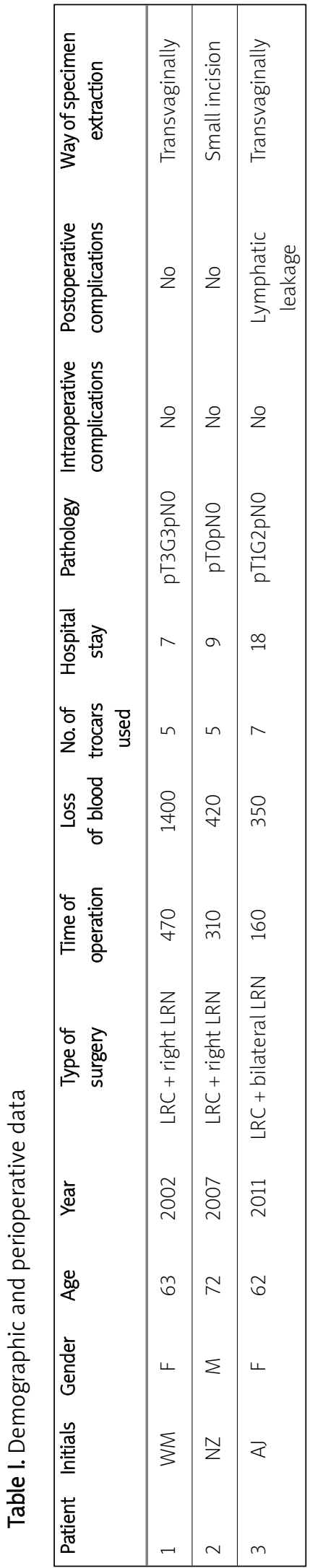




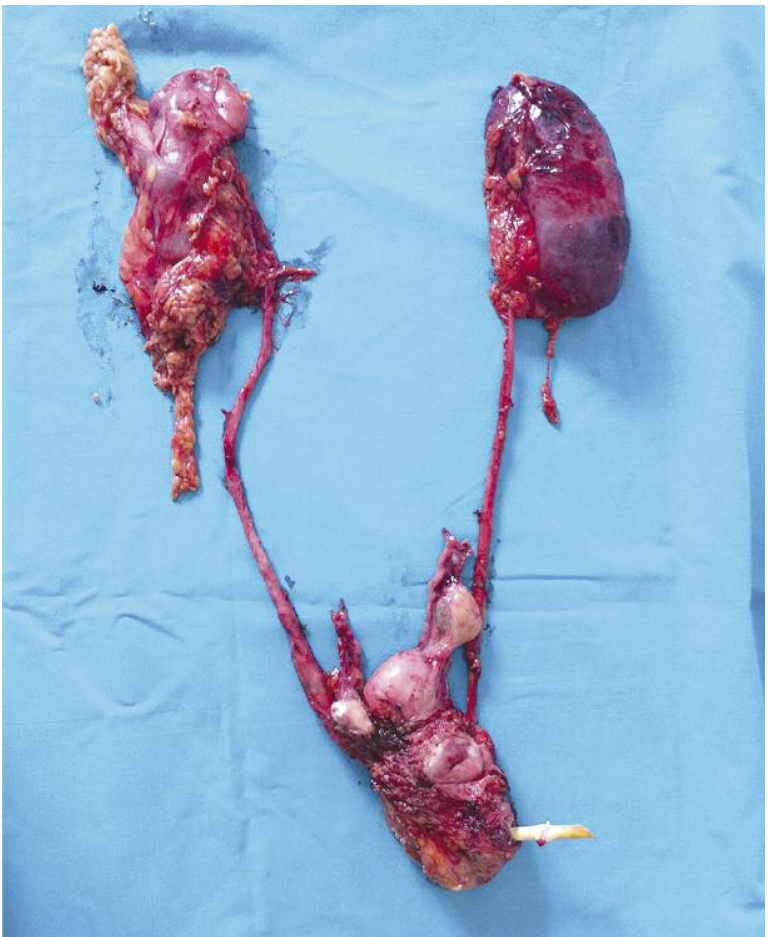

Photo 1 . The specimen removed after total exenteration of the urinary tract

time was $470 \mathrm{~min}, 310 \mathrm{~min}$ and $160 \mathrm{~min}$ respectively. In patient 3 the postoperative course was complicated with prolonged lymphatic leakage from the drain. In the remaining two cases the postoperative course was smooth and uneventful.

\section{Discussion}

The procedure of complete urinary exenteration is applied in some centers in the treatment of simultaneous bladder and bilateral upper urinary tract TCC tumors, as well as for uremic, dialysis-dependent end-stage renal disease [15-20]. It has been suggested that these latter types of patients have more progressive cancers [16, 21]. Multifocal TCC has also been reported as an indication for complete genitourinary exenteration in renal transplant recipients, as the development of cancerogenesis following organ transplantation has been linked to the use of immunosuppressive agents [22]. In our material only in case 3 were the disseminated TCC lesions the indication for the surgery. In the remaining two cases simultaneous unilateral nephroureterectomy was performed due to hydronephrosis and the lack of function in the course of bladder cancer causing the obstruction of the intramural part of the ureters. Sin- gle-session nephroureterectomy with pelvic lymph node dissection and radical cystectomy is a challenging procedure, particularly when performed laparoscopically. Special care must be taken intraoperatively to provide the lowest possibility of tumor spillage. In order to follow oncological rules, the specimen should be extracted en-bloc with the bladder neck closed to avoid contact of urine with the abdominal cavity. After complete dissection of the specimen, which should also include prostate and seminal vesicles in men and reproductive organs in women, it has to be immediately entrapped in an endoscopy bag. Some surgeons prefer to perform bilateral nephroureterectomy with [16] or without [6] hand assistance and later to conduct cystectomy and pelvic lymph node dissection under direct vision using standard open surgical technique. Although we agree that hand-assisted surgery may have the advantage of tactile feedback, and it may also enable digital retraction and dissection of tissues and organs, we did not use this technique in the described cases. In our opinion hand-assisted laparoscopy may be helpful particularly for beginners. Radical cystectomy is a typical ablative procedure; thus in female patients the anterior wall of the vagina should also be resected. Therefore, it is necessary to close it with interrupted or running sutures, which requires skill in laparoscopic suturing. The excised specimen can be removed through a small lower midline [14, 22, 23], Pfannenstiel incision [17, 18] or transvaginally in female patients [4, 20]. In 2004 Deger et al. reported a series of 20 laparoscopic cystectomies with an intracorporeal rectosigmoid pouch where specimens were removed transanally in men and transvaginally in women [24]. In two female patients from our series the vagina was used as the way of extraction since the procedure included excision of the anterior wall of the vagina anyway.

In conclusions, laparoscopic techniques are expanding in uro-oncology and in most cases have become routine procedures. They can also be safely used in selected cases of total or partial exenteration of the urinary tract as an alternative modality to the open counterpart for surgeons with advanced laparoscopic skills.

\section{References}

1. Oldbring J, Glifberg I, Mikulowski P, Hellsten S. Carcinoma of the renal pelvis and ureter following bladder carcinoma: fre- 
quency, risk factors, and clinicopathological findings. J Urol 1989; 141: 1311-3.

2. Holmaeng S, Johansson SL. Synchronous bilateral ureteral and renal pelvic carcinomas. Cancer 2004; 101: 741-7.

3. Gill IS, Fergany A, Klein EA, et al. Laparoscopic radical cystoprostatectomy with ileal conduit performed completely intracorporeally: the initial 2 cases. Urology 2000; 56: 26-30.

4. Słojewski M, Gołąb A, Sikorski A. Laparoscopic cystectomy own experience based on two cases. Urol Pol 2002; 55: 81-5.

5. Stojewski M, Chłosta P. Cystektomia laparoskopowa. In: Atlas laparoskopii urologicznej. P. Chłosta, M. Słojewski (eds.). Polskie Towarzystwo Urologiczne, Warsaw 2008; 158-170.

6. Szydełko T, Kasprzak J, Apoznański W, et al. Bilateral nephroureterectomy with open cystoprostatectomy for simultaneous upper urinary tract carcinoma. CEJU 2009; 2: 101-3.

7. Chtosta P, Drewa T, Dobruch J, et al. Is pure laparoscopic radical cystectomy still an attractive solution for the treatment of muscle-invasive bladder cancer? Urol Int 2010; 85: 291-5.

8. Clayman RV, Kavoussi LR, Soper NJ, et al. Laparoscopic nephrectomy: initial case report. J Urol 1991; 146: 278-82.

9. Clayman RV, Kavoussi LR, Figenshau RS, et al. Laparoscopic nephroureterectomy: initial clinical case report. J Laparoendosc Surg 1991; 1: 343-9.

10. Parra RO, Andrus CH, Jones JP, Boullier JA. Laparoscopic cystectomy: initial report on a new treatment for the retained bladder. J Urol 1992; 148: 1140-4.

11. Sánchez de Badajoz E, Gallego Perales JL, Reche Rosado A, et al. Laparoscopic cystectomy and ileal conduit: case report. J Endourol 1995; 9: 59-62.

12. Rassweiler J, Godin K, Goezen AS, et al. Radical cystectomy - pro laparoscopic. Urologe A 2012; 51: 671-8.

13. Khan MS, Challacombe B, Elhage O, et al. A dual-centre, cohort comparison of open, laparoscopic and robotic-assisted radical cystectomy. Int I Clin Pract 2012; 66: 656-62.

14. Chtosta P, Drewa T, Siekiera J, et al. Lymph node dissection during laparoscopic (LRC) and open (ORC) radical cystectomy due to muscle invasive bladder urothelial cancer (pT2-3, TCC). Videosurgery Miniinv 2011; 6: 127-31.

15. Ou CU, Yang WH. Complete urinary tract exenteration for dialysis patient with urothelial cancer: lower midline and extraperitoneal approach in a supine position. Urology 2011; 77: 1244-7.

16. Lin VC, Hung KC, Chen MJ, et al. Single-session laparoscopic total urinary tract exenteration without repositioning for multifocal urothelial carcinoma in dialysis-dependent patients. Urology 2011; 77: 98-103.

17. Barros R, Frota R, Stein RJ, et al. Simultaneous laparoscopic nephroureterectomy and cystectomy: a preliminary report. Int Braz I Urol 2008; 34: 413-21.

18. Berglund RK, Matin SF, Desai M, et al. Laparoscopic radical cystoprostatectomy with bilateral nephroureterectomy: initial report. BJU Int 2005; 97: 37-41.

19. Li CC, Wang HS, Wu WJ, et al. Laparoscopic complete urinary tract exenteration with the specimen withdrawn transvaginally. BJU Int 2009; 104: 82-6.

20. Yuan LH, Chung HJ, Chen KK. Laparoscopic radical cystectomy combined with bilateral nephroureterectomy and specimen extraction through the vagina. J Chin Med Assoc 2007; 70: 260-1.
21. Takehara K, Nishikido M, Koga S, et al. Multifocal transitional cell carcinoma associated with renal carcinoma in a patient on long-term haemodialysis. Nephrol Dial Transplant 2002; 17: 1692-4.

22. Glassman DT, Sklar GN. Complete genitourinary exenteration for multifocal transitional cell carcinoma in renal transplant recipient. J Urol 2001; 166: 986-7.

23. Chłosta P, Drewa T, Obarzanowski M, et al. Do we reed a cosmetics effect for radical nephrectomy? Laparoendoscopic single-site surgery would help to answer this question. Videosurgery Miniinv 2011; 6: 1-4.

24. Deger S, Peters R, Roigas J, et al. Laparoscopic radical cystectomy with continent urinary diversion (rectosigmoid pouch) performed completely intracorporeally: an intermediate functional and oncologic analysis. Urology 2004; 64: 935-9.

Received: 12.07.2012, revised: 8.09.2012, accepted: 24.09.2012. 